\title{
Finely Tuned Structure and Catalytic Performance of Cerium Oxides by a \\ Continuous Samarium Doping from 0 to 100\%
}

Ran Tao, ${ }^{* a}$ Jingsong Xu, ${ }^{a}$ Hang Zhong, ${ }^{a}$ Wen Wen, ${ }^{b}$ Qifa Pan, ${ }^{a}$ Yong Liu, ${ }^{c}$ and Jun

$$
\text { Chen *,a }
$$

a Science and Technology on Surface Physics and Chemistry Laboratory, Jiangyou 621907, Sichuan, China.

b Shanghai Synchrotron Radiation Facility, Shanghai Institute of Applied Physics, China Academy of Science, Shanghai 201204, China.

${ }^{c}$ Institute of Materials, China Academy of Engineering Physics, Mianyang 621908, Sichuan, China. 

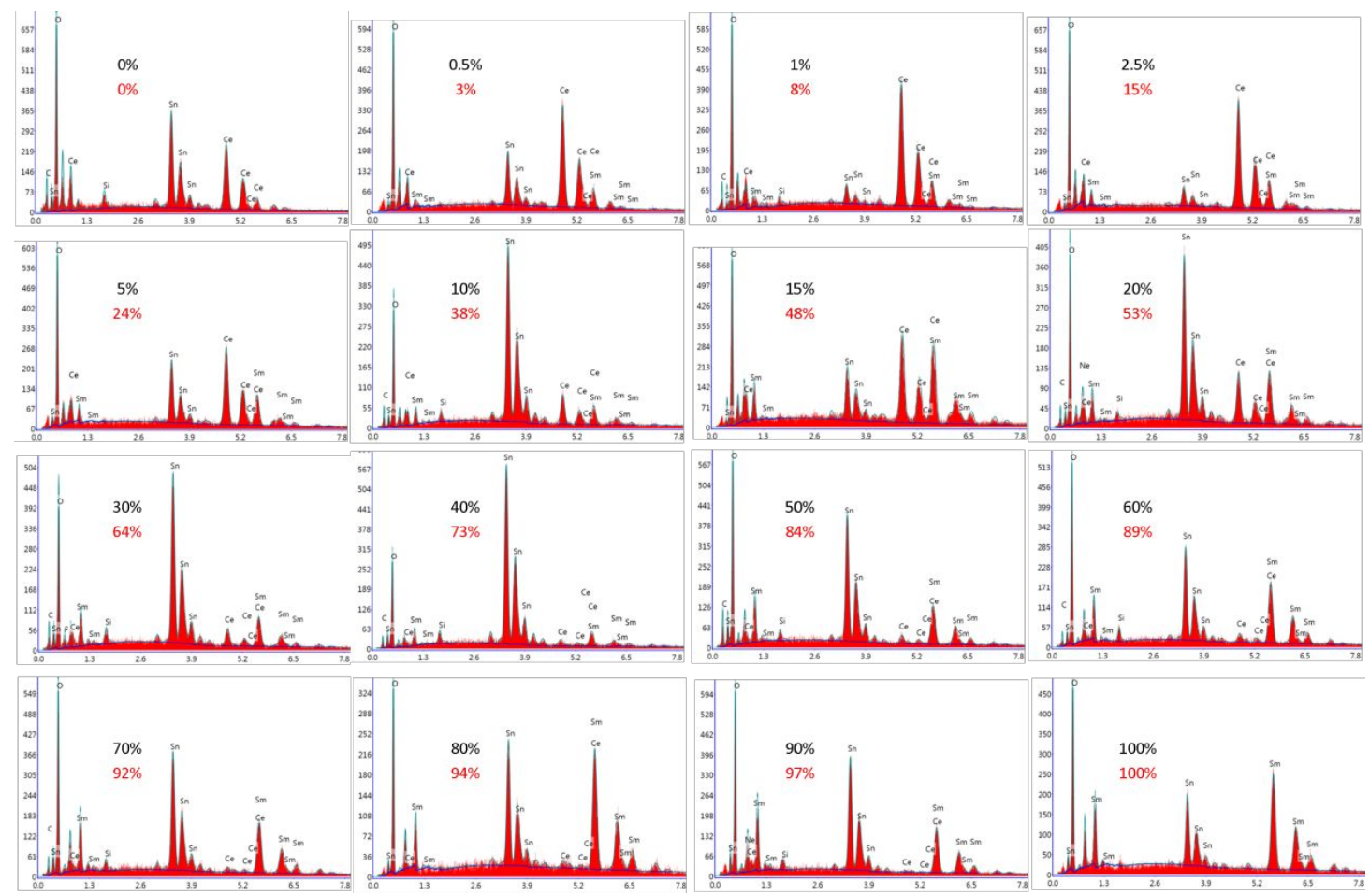

Figure S1. The EDS analysis of $\mathrm{Sm}^{3+}$ concentration in $\mathrm{Sm}_{\mathrm{x}} \mathrm{Ce}_{1-\mathrm{x}} \mathrm{O}_{2-\delta}$ films (The corresponding results are marked in red, while the data of the initial doping concentration in deposition solutions are in black). 


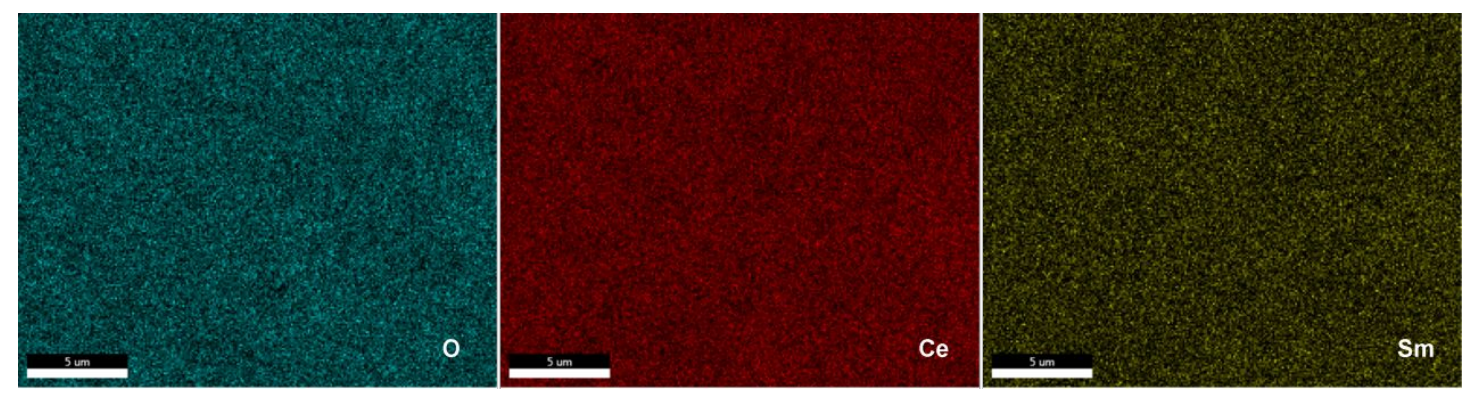

Figure S2. EDS surface scanning of the $\mathrm{Sm}_{0.24} \mathrm{Ce}_{0.76} \mathrm{O}_{1.88}$ film. 

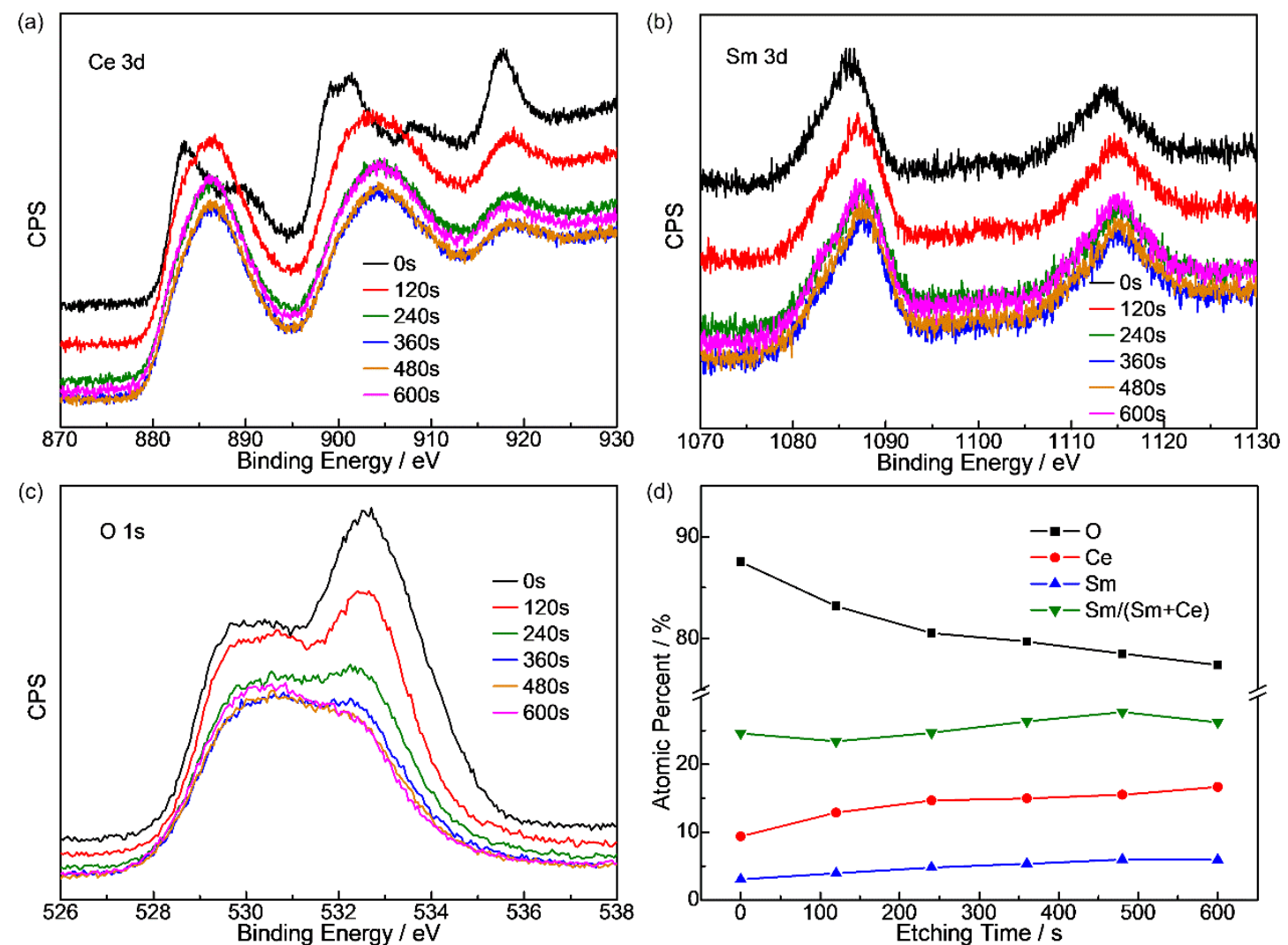

Figure S3. The Ce 3d (a), Sm 3d (b), and O 1s (c) XPS spectra of the $\mathrm{Sm}_{0.24} \mathrm{Ce}_{0.76} \mathrm{O}_{1.88}$ film sputtered by $\mathrm{Ar}^{+}$ion for $0 \sim 600 \mathrm{~s}$, and corresponding compositional variation with sputtering time (d). 

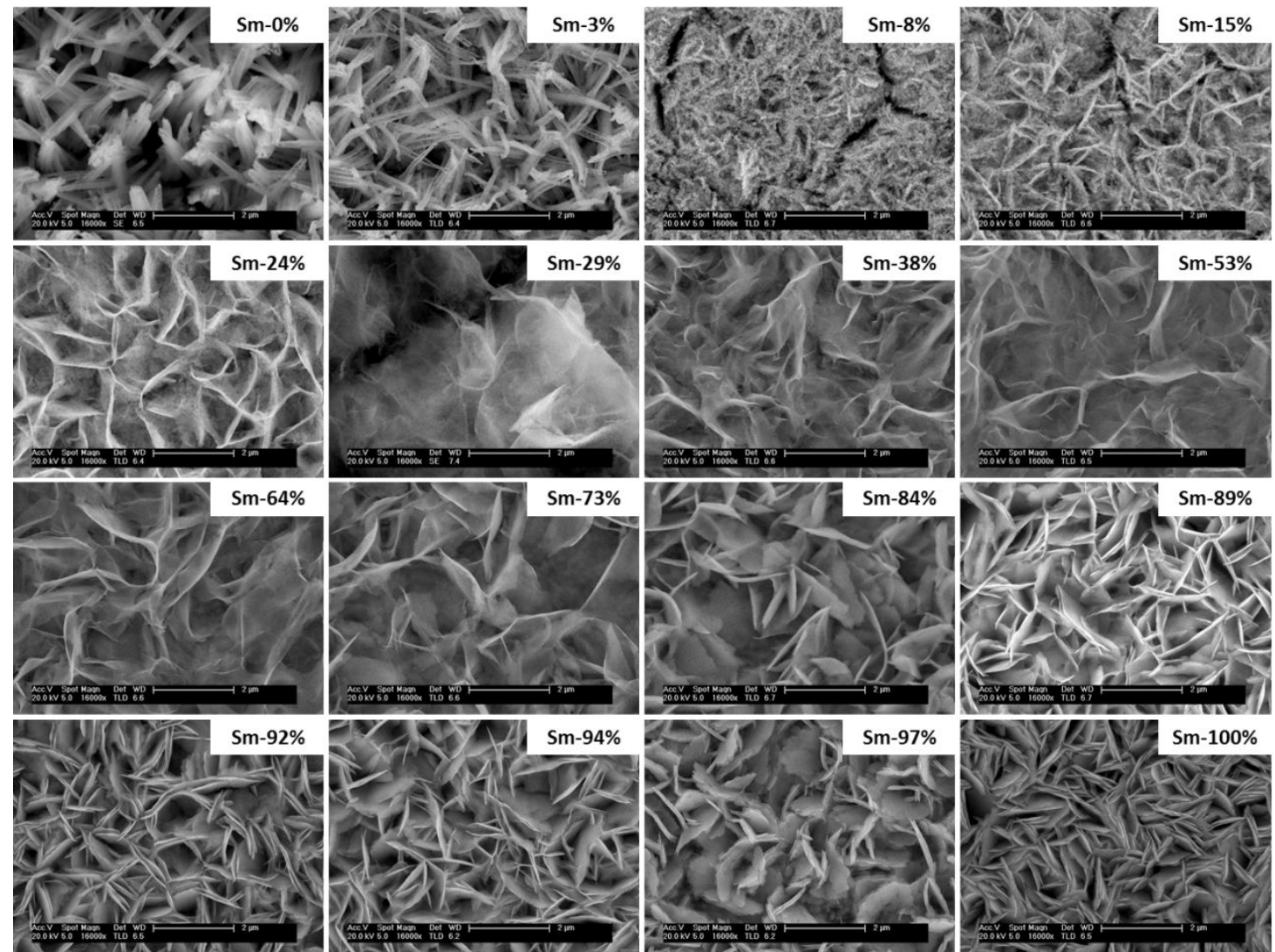

Figure S4. SEM images of $\mathrm{Sm}_{\mathrm{x}} \mathrm{Ce}_{1-\mathrm{x}} \mathrm{O}_{2-\delta}$ films with the $\mathrm{Sm}^{3+}$ concentration ranging from $0 \%$ to $100 \%$. 

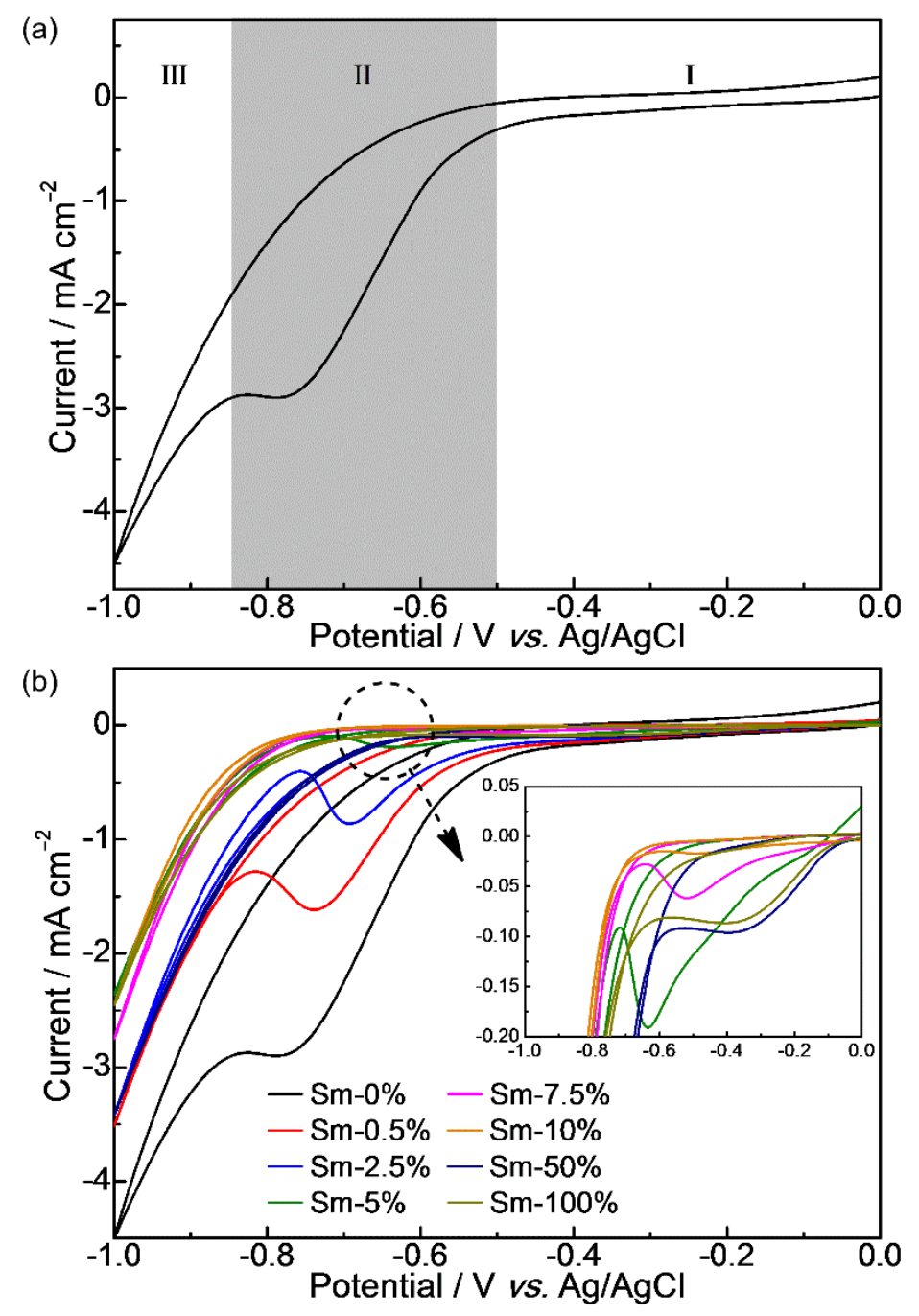

Figure S5. (a) $\mathrm{CV}$ performed on FTO substrate in $50 \mathrm{mM} \mathrm{Ce}\left(\mathrm{NO}_{3}\right)_{3}$ solution at $70^{\circ} \mathrm{C}$, and (b) the comparison of CV curves obtained in the electrolyte comprised of $50 \mathrm{mM}$ $\mathrm{Ce}\left(\mathrm{NO}_{3}\right)_{3} / \mathrm{Sm}\left(\mathrm{NO}_{3}\right)_{3}$ mixture. The portion of $\mathrm{Sm}\left(\mathrm{NO}_{3}\right)_{3}$ ranges from 0 to $100 \mathrm{~mol} \%$. 

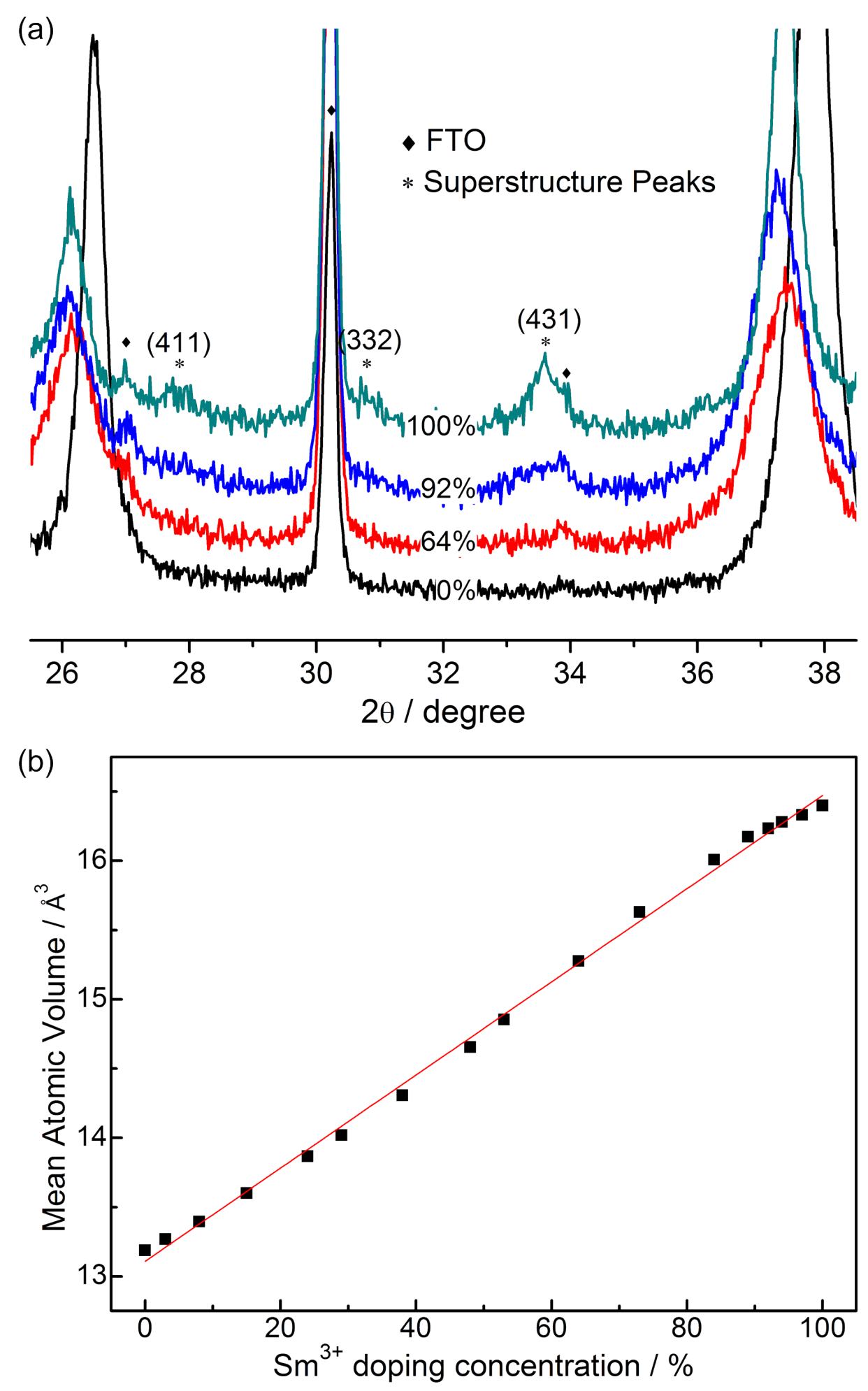

Figure S6. (a) The enlarged XRD picture showing the diffraction peaks of superstructures in the C-type samples and (b) trend of the mean atomic volume as a function of the $\mathrm{Sm}^{3+}$ concentration in $\mathrm{Sm}_{\mathrm{x}} \mathrm{Ce}_{1-\mathrm{x}} \mathrm{O}_{2-\delta}$ nanocrystals (the regression line is shown in red). 

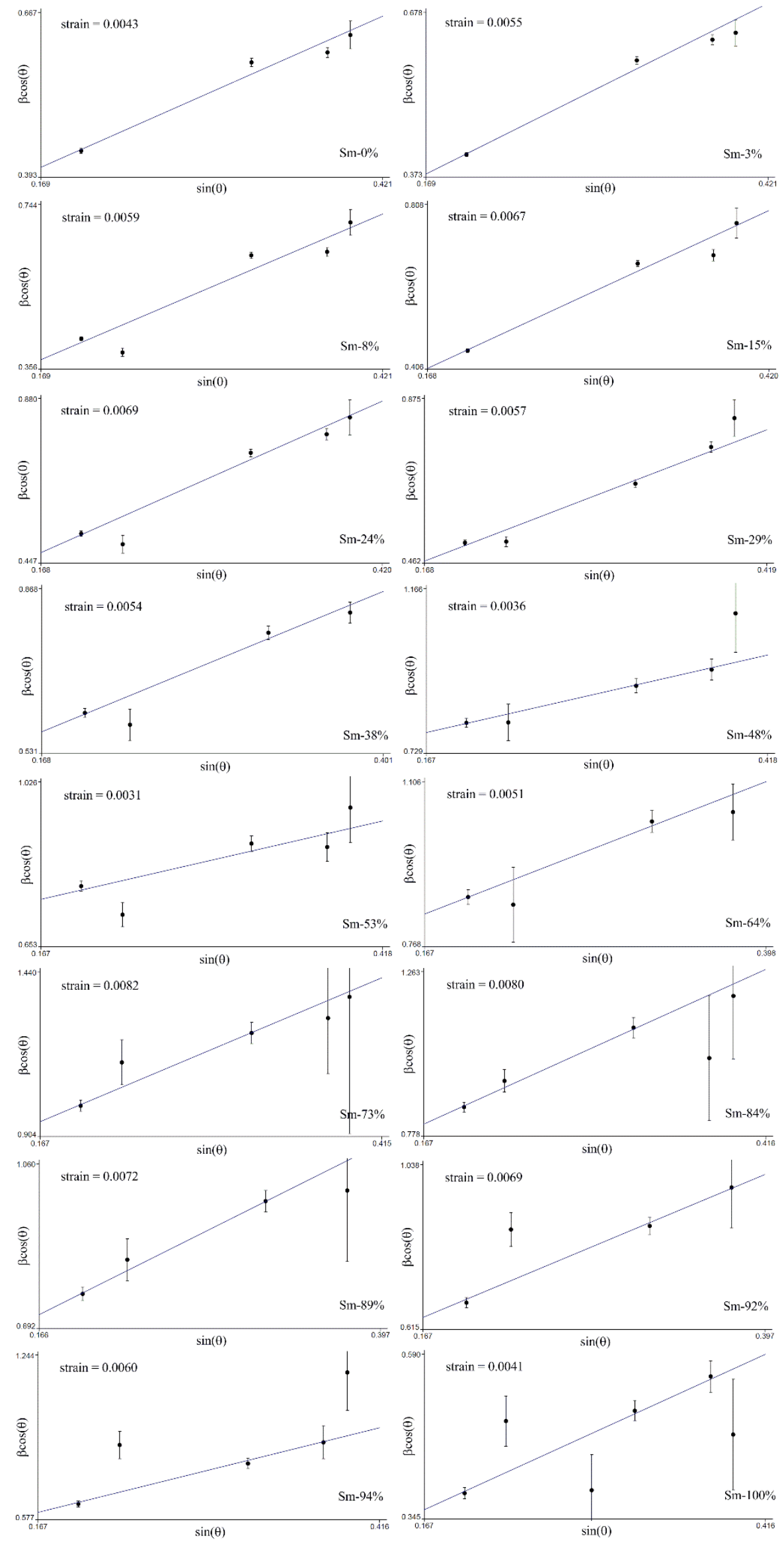

Figure S7. Williamson-Hall plots of $\mathrm{Sm}_{\mathrm{x}} \mathrm{Ce}_{1-\mathrm{x}} \mathrm{O}_{2-\delta}(\mathrm{x}=0 \sim 1)$ nanocrystals. 


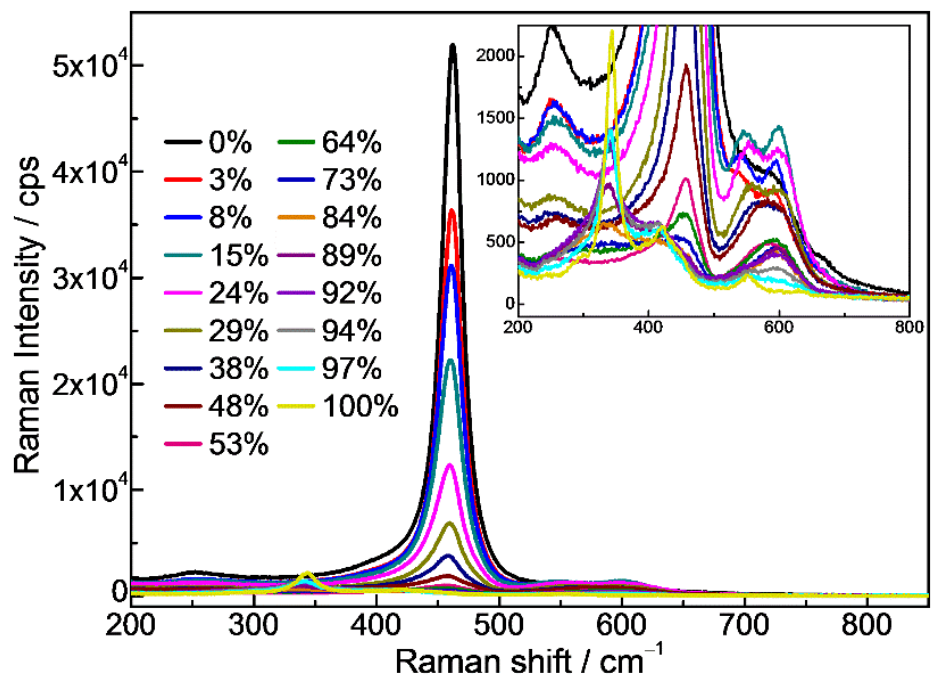

Figure S8. Raman spectra of $\mathrm{Sm}_{\mathrm{x}} \mathrm{Ce}_{1-\mathrm{x}} \mathrm{O}_{2-\delta}$ nanocrystals with the concentration of $\mathrm{Sm}^{3+}$ varying from $0 \%$ to $100 \%$. 
(a)

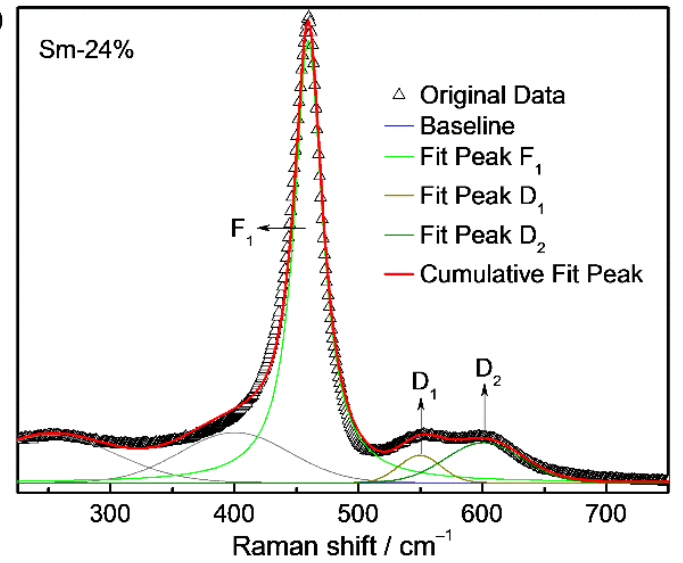

(b)

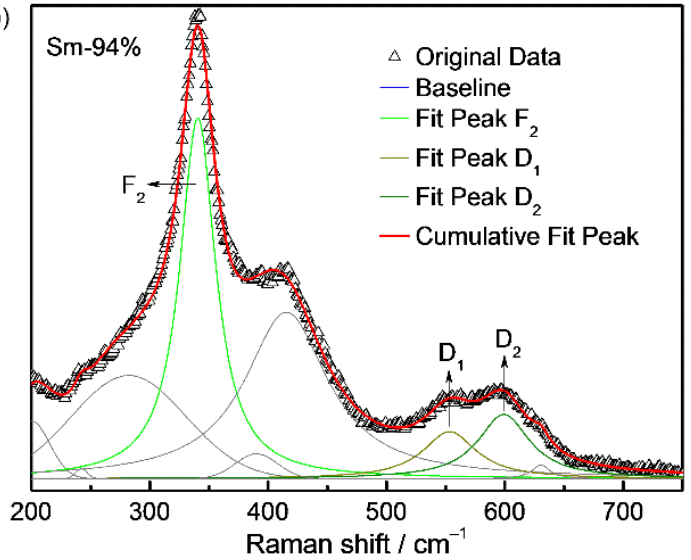

Figure S9. Examples of Raman spectra deconvolved by Lorentzian and Gaussian fitting. 

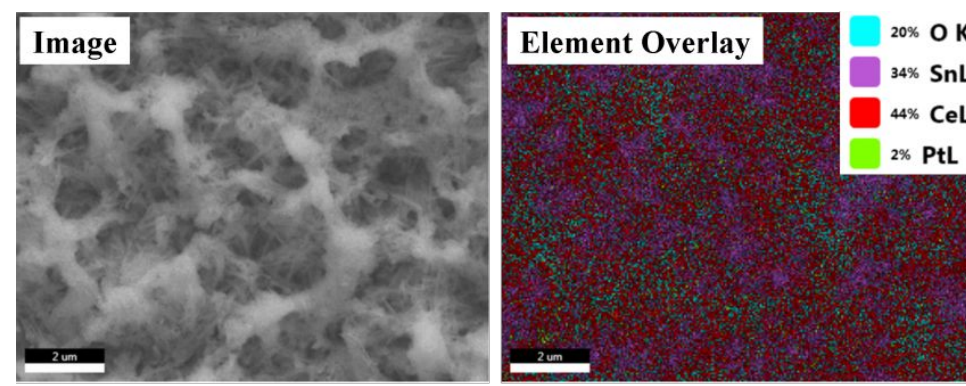

Sn
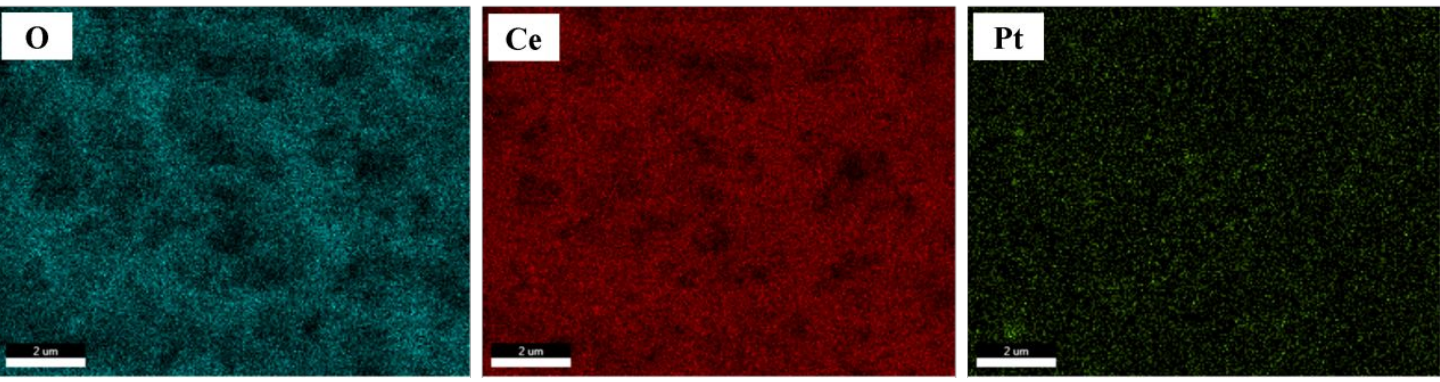

Figure S10. SEM and EDS surface scanning images of $\mathrm{Pt} / \mathrm{CeO}_{2} / \mathrm{FTO}$. The signals of

Sn and O partially, come from the FTO substrate. 

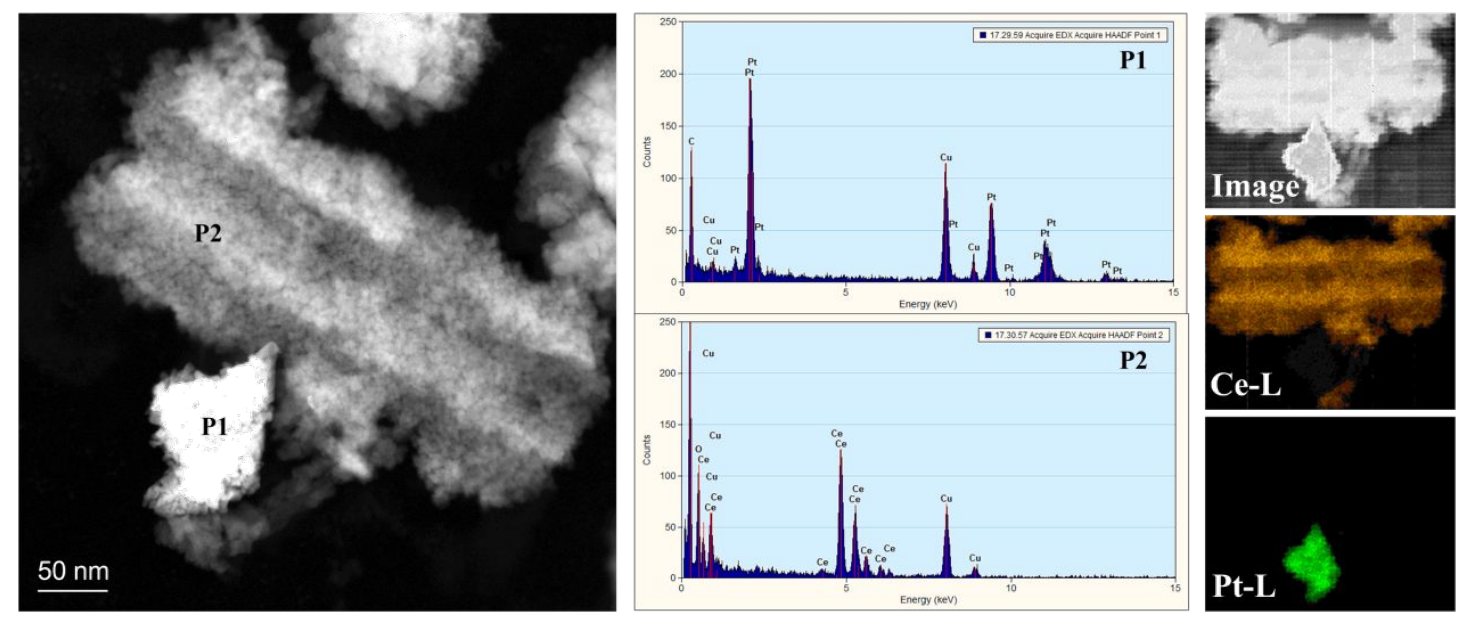

Figure S11. STEM high-angle annular dark field (HAADF) images (left), EDS point (middle) and surface (right) scanning results of $\mathrm{Pt} / \mathrm{CeO}_{2}$. 


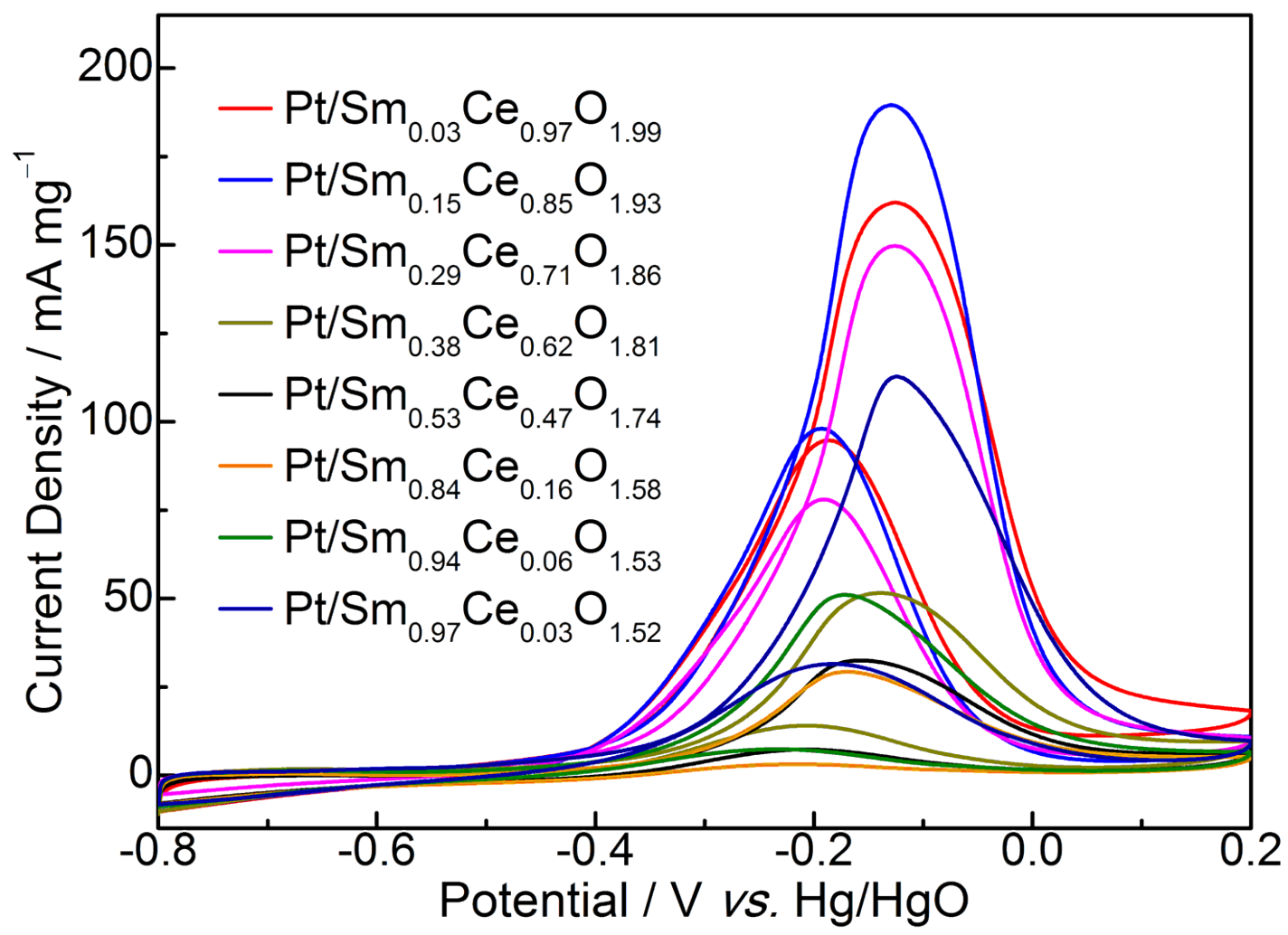

Figure S12. $\mathrm{CV}$ curves of $\mathrm{Pt} / \mathrm{Sm}_{\mathrm{x}} \mathrm{Ce}_{1-\mathrm{x}} \mathrm{O}_{2-\delta}$ in $1 \mathrm{M} \mathrm{KOH}+1 \mathrm{M} \mathrm{CH}_{3} \mathrm{OH}$ solution at 50 $\mathrm{mV} / \mathrm{s}$. 
Table S1. Deconvolution results of the $\mathrm{Pt} 4 f$ spectra, the contents of $\mathrm{Pt}^{0}$ and $\mathrm{Pt}^{2+}$ are given in percentage of total intensity.

\begin{tabular}{|c|c|c|c|c|}
\hline \multirow{2}{*}{ Sample } & \multicolumn{2}{|l|}{$\mathbf{P t}^{\mathbf{0}}$} & \multicolumn{2}{|l|}{$\mathbf{P t}^{2+}$} \\
\hline & Binding Energy /eV & Ratio $/ \%$ & Binding Energy /eV & Ratio /\% \\
\hline \multirow{2}{*}{ Pt } & 71.14 & \multirow{2}{*}{52.45} & 71.97 & \multirow{2}{*}{47.55} \\
\hline & 74.47 & & 75.35 & \\
\hline \multirow{2}{*}{$\mathrm{Pt} / \mathrm{CeO}_{2}$} & 71.18 & \multirow{2}{*}{57.79} & 71.75 & \multirow{2}{*}{42.21} \\
\hline & 74.54 & & 75.63 & \\
\hline \multirow{2}{*}{$\mathbf{P t} / \mathrm{Sm}_{0.24} \mathrm{Ce}_{0.76} \mathrm{O}_{1.88}$} & 70.12 & \multirow{2}{*}{66.65} & 71.04 & \multirow{2}{*}{33.35} \\
\hline & 73.44 & & 74.32 & \\
\hline \multirow{2}{*}{$\mathrm{Pt} / \mathrm{Sm}_{0.64} \mathrm{Ce}_{0.36} \mathrm{O}_{1.68}$} & 71.07 & \multirow{2}{*}{57.19} & 71.69 & \multirow{2}{*}{42.81} \\
\hline & 74.42 & & 75.23 & \\
\hline \multirow{2}{*}{$\mathrm{Pt} / \mathrm{Sm}_{2} \mathrm{O}_{3}$} & 71.02 & \multirow{2}{*}{60.88} & 72.03 & \multirow{2}{*}{39.12} \\
\hline & 74.33 & & 75.26 & \\
\hline
\end{tabular}

